\title{
Effect of chemical form, heating, and oxidation products of linoleic acid on rumen bacterial population and activities of biohydrogenating enzymes
}

\author{
A. Kaleem, ${ }^{*} \dagger \ddagger$ F. Enjalbert, ${ }^{*} \dagger \ddagger$ Y. Farizon, ${ }^{*} \dagger \ddagger$ and A. Troegeler-Meynadier ${ }^{*}+\ddagger^{1}$ \\ *Université de Toulouse INPT ENVT, UMR1289 Tissus Animaux Nutrition Digestion Ecosystème et Métabolisme, F-31076 Toulouse, France \\ †INRA, UMR1289 Tissus Animaux Nutrition Digestion Ecosystème et Métabolisme, F-31326 Castanet-Tolosan, France \\ †Université de Toulouse INPT ENSAT, UMR1289 Tissus Animaux Nutrition Digestion Ecosystème et Métabolisme, \\ F-31326 Castanet-Tolosan, France
}

\begin{abstract}
Heating polyunsaturated fatty acids (PUFA) produces oxidation products, such as hydroperoxides, aldehydes, and oxypolymers, which could be responsible at least in part for modification of PUFA rumen biohydrogenation (BH). Three in vitro experiments were conducted to investigate the effects of linoleic acid (cis-9,cis-12-C18:2) oxidation products on BH. In the first experiment, we studied the effects of free linoleic acid (FLA), heated FLA (HFLA, at $150^{\circ} \mathrm{C}$ for $6 \mathrm{~h}$ ), triacylglycerols of linoleic acid (TGLA), heated TGLA (HTGLA, at $150^{\circ} \mathrm{C}$ for $6 \mathrm{~h}$ ), 13-hydroperoxide (13HPOD), trans-2-decenal (T2D), and hexanal (HEX) on $\mathrm{BH}$ in vitro after 6 and $24 \mathrm{~h}$ of incubation. In the second experiment, aldehydes differing in chain length and degree of unsaturation [pentanal, HEX, heptanal, nonanal, T2D, trans-2,trans-4-decadienal (T2T4D)] were incubated in vitro for $5 \mathrm{~h}$ in rumen fluid. In the third experiment, 9-hydroperoxide (9HPOD), 13HPOD, HEX, or T2T4D were incubated for $1 \mathrm{~h}$ in rumen fluid inactivated with chloramphenicol to investigate their effects on enzyme activity. In experiment 1 , heat treatment of TGLA generated TGLA oxypolymers, did not affect cis-9,cis-12-C18:2 disappearance, but did decrease BH intermediates, especially trans-11 isomers. Heating FLA decreased cis-9,cis-12-C18:2 disappearance and cis-9,trans-11-CLA and trans-11-C18:1 production. Treatment with HEX and T2D did not affect cis-9, cis-12-C18:2 disappearance and barely affected production of $\mathrm{BH}$ intermediates. The bacterial community was affected by 13HPOD compared with FLA and HFLA, in parallel with an increase in trans-10 isomer production after a 6 -h incubation. After $24 \mathrm{~h}$ of incubation, 13HPOD decreased trans-11 isomer production, but to a lesser extent than HFLA. In experiment 2, some weak but significant effects were observed on $\mathrm{BH}$, unrelated to chain length or degree of
\end{abstract}

Received March 7, 2013.

Accepted July 12, 2013.

${ }^{1}$ Corresponding author: a.troegeler@envt.fr unsaturation of aldehydes; the bacterial community was not affected. In experiment 3, 9HPOD inhibited $\Delta^{9}$ isomerization, and both 9HPOD and 13HPOD inhibited $\Delta^{12}$-isomerization. We concluded that oxypolymers did not affect cis-9,cis-12-C18:2 disappearance. Heating both esterified and free cis-9,cis-12-C18:2 greatly altered $\Delta^{12}$-isomerization. Aldehydes had few effects. Hydroperoxides are responsible, at least in part, for the effects of fat heating: 13HPOD increased trans-10 isomer production (probably by affecting the bacterial community) and decreased trans-11 isomer production by inhibiting $\Delta^{12}$-isomerase activity, whereas 9HPOD inhibited both isomerases.

Key words: rumen biohydrogenation, lipid oxidation, linoleic acid, trans fatty acids

\section{INTRODUCTION}

Trans FA, including various trans-octadecenoic acid (trans-C18:1) isomers and most conjugated linoleic acid (CLA) isomers, which are positional and geometric isomers of linoleic acid (cis-9,cis-12-C18:2) with conjugated double bonds, have been reported to potentially affect the risk of cancer and cardiovascular diseases in humans (Gebauer et al., 2011). Among CLA isomers, cis-9,trans-11-CLA has beneficial properties for human health, whereas trans-10,cis-12-CLA may be harmful (Troegeler-Meynadier and Enjalbert, 2005). Many human foods contain trans FA, with dairy products having the highest concentrations. In dairy cows, milk trans FA have 2 origins. The first is microbial ruminal biohydrogenation (BH) of cis-9,cis-12-C18:2, which begins with isomerization, mainly producing cis9,trans-11-CLA and trans-10,cis-12-CLA (Enjalbert and Troegeler-Meynadier, 2009). Thereafter, initial reduction produces different trans-C18:1, in particular trans-11-C18:1 (vaccenic acid) and trans-10-C18:1. Finally, a subsequent reduction produces stearic acid (C18:0). Butyrivibrio fibrisolvens is believed to be responsible for the production of cis-9,trans-11-CLA and trans-11-C18:1 (Enjalbert and Troegeler-Meynadier, 
2009), whereas Megasphera elsdenii (Kim et al., 2002) and Propionibacterium acnes (Wallace et al., 2007) have been reported to form trans-10,cis-12-CLA in vitro. A more significant origin of milk CLA is mammary desaturation of trans-11-C18:1 into cis-9,trans-11-CLA (Griinari et al., 2000). trans-11-C18:1 is an intermediate of ruminal $\mathrm{BH}$ of both cis-9,cis-12-C18:2 and o-linolenic acid (cis-9,cis-12,cis-15-C18:3). Thus, milk CLA content could be influenced both by factors affecting cis-9,cis-12-C18:2 and cis-9,cis-12,cis-15-C18:3 BH and by factors affecting desaturation in the mammary gland.

One way to efficiently increase CLA milk concentration is the addition of a fat supplement to the dairy cow diet, particularly a fat source rich in cis-9,cis-12-C18:2 or cis-9,cis-12,cis-15-C18:3. In dairy cow diets, fat is usually provided by oilseeds, which are often heat treated; for example, by roasting or extrusion. These processes have been shown to have variable effects on $\mathrm{BH}$ in different studies, which need to be described and explained. Heating oilseeds often induces a decrease in cis-9,cis-12-C18:2 and cis-9,cis-12,cis-15-C18:3 BH in vivo (Gonthier et al., 2005), in situ (TroegelerMeynadier et al., 2006b), and in vitro (Reddy et al., 1994; Kaleem et al., 2013). Furthermore, heat treatment of oilseeds results in increased milk proportions of BH intermediates, particularly cis-9,trans-11-CLA and trans-11-C18:1 (Chouinard et al., 1997a,b; Chilliard et al., 2009).

A previous study in our laboratory (Privé et al., 2010) showed that increasing the heating temperature of sunflower oil led to partial protection of PUFA against BH in vitro, but contrary to previous reports with heated oilseeds, heated oil increased trans-10 isomers and decreased trans-11 isomers. These effects were linked to the peroxide value of oil and associated with a modification of the bacterial community. More recently, a study with heated oilseeds (Kaleem et al., 2013) showed that aldehydes, in particular hexanal (HEX), were linked to a decrease in PUFA disappearance in ruminal cultures.

These changes in $\mathrm{BH}$ caused by heated fat could be mediated by potentially active molecules generated during heat treatment: the lipid oxidation products (mostly FA hydroperoxides and aldehydes). Oxidation of cis-9,cis-12-C18:2 can be divided into 3 steps (Frankel, 2005). During initiation, cis-9,cis-12-C18:2 is converted to an alkyl radical. During propagation, oxygen binds with this radical forming a peroxyl radical, which takes a hydrogen radical from another cis-9, cis-12-C18:2, forming a hydroperoxide [13OOHcis-9,trans-11-linoleate (13HPOD) and 9OOH-trans10, cis-12-linoleate (9HPOD) for cis-9,cis-12-C18:2] and spreading the oxidation reaction to other FA. The third step is termination, which may produce hydroxy- acids, aldehydes, ketones, or triacylglycerol (TAG) oxypolymers.

A hypothesis for the action of oxidative products on $\mathrm{BH}$ is that hydroperoxides could interfere with $\mathrm{BH}$ reactions through competitive inhibition of enzymes because of their structural similarity to PUFA and mainly CLA. Moreover, hydroperoxides could be toxic to bacteria because they have been shown to inhibit the activity of rumen anaerobic microorganisms (Brioukhanov and Netrusov, 2004). Aldehydes have also been reported to have toxic effects on rumen bacteria, depending on their chain length (Kubo et al., 1995) and degree of unsaturation (Deng et al., 1993), and some have been shown to promote $\mathrm{BH}$, in particular trans2-decenal (T2D; Lee et al., 2007). They also could protect PUFA from $\mathrm{BH}$, in particular HEX (Kaleem et al., 2013). Moreover, TAG oxypolymers could be less sensitive to lipases because of their steric hindrance, resulting in a partial protection of PUFA from $\mathrm{BH}$ (as only free FA can be hydrogenated by rumen bacteria).

The objectives of this study were to investigate whether TAG oxypolymers, hydroperoxides, or aldehydes were responsible, at least in part, for the $\mathrm{BH}$ alterations observed with heated fat, focusing particularly on the effects of chain length and degree of unsaturation of aldehydes. Moreover, as a first mechanistic approach, we studied the effects of oxidation products on the bacterial community, using an overall quantitative and qualitative approach, and the effects on enzymatic activities using chloramphenicol to prevent synthesis of enzymes during ruminal incubation.

\section{MATERIALS AND METHODS}

Three experiments were conducted in vitro: the first explored the effect on $\mathrm{BH}$ and rumen bacteria of TAG oxypolymers, obtained by heating TAG, and the effects of heating pure cis-9,cis-12-C18:2 or adding pure 13HPOD or 2 pure aldehydes (HEX and T2D); the second investigated the effect of aldehyde chain length and degree of unsaturation on rumen $\mathrm{BH}$ and bacteria. The third investigated the effects of 13HPOD and 9HPOD and 2 aldehydes (HEX and trans-2,trans-4-decadienal, T2T4D) on BH enzyme activities.

\section{In Vitro Incubations}

Experiment 1. As there is no available commercial preparation of TAG oxypolymer, we produced these compounds by heating pure TAG of cis-9, cis-12-C18:2 (TGLA, purity $\geq 99 \%$, Sigma Co., St Louis, MO) at $150^{\circ} \mathrm{C}$ for $6 \mathrm{~h}$, resulting in heated TGLA (HTGLA). Pure cis-9, cis-12-C18:2 (free linoleic acid, FLA, purity $\geq 99 \%$, Sigma Co.) was heated separately at $150^{\circ} \mathrm{C}$ for 
$6 \mathrm{~h}$, resulting in heated FLA (HFLA). Once heated, TGLA and FLA were left at ambient temperature for 30 min before storage at $-80^{\circ} \mathrm{C}$ until utilization. For hydroperoxides, 13HPOD was synthesized in the laboratory from pure cis-9,cis-12-C18:2 using the methods of Fauconnier et al. (1997) and López-Nicolás et al. (1999). Briefly, cis-9,cis-12-C18:2 was incubated in a $\mathrm{pH} 9$ borate buffer $(0.2 \mathrm{M})$ at $0^{\circ} \mathrm{C}$ for $30 \mathrm{~min}$ with soybean lipoxygenase as the catalyst, under constant aeration. Then, the $\mathrm{pH}$ of the buffer solution was adjusted to 3 using $3 \mathrm{~N} \mathrm{HCl}$ and the solution was purified on a solid-phase cartridge (Strata C18-E, $500 \mathrm{mg}$, Phenomenex, Le Pecq, France). The 13HPOD was eluted with ethanol, which was then evaporated under vacuum at $40^{\circ} \mathrm{C}$. Once the solvent was completely eliminated, the samples were placed in small bottles filled with nitrogen and stored at $-80^{\circ} \mathrm{C}$ until further use. Before the experiment, 13HPOD in this preparation was quantified as described later: purity was $78 \%$. The 2 aldehydes, HEX and T2D, used in the experiment were those already shown to modify BH (Kaleem et al., 2013 and Lee et al., 2007, respectively) and were of commercial origin (purity $\geq 97 \%$ and $\geq 95 \%$, respectively, Sigma Co.). Ruminal cultures were performed in a water bath rotary shaker (Aquatron; Infors AG, Bottmingen, Germany). Rumen contents were collected from a lactating dairy cow fed a corn silage-based diet (29.6 kg of corn silage, $2 \mathrm{~kg}$ of soybean meal, and $0.2 \mathrm{~kg}$ of a mineral and vitamin supplement, as fed) in 2 equal meals. The cow was adapted to this diet for $18 \mathrm{~d}$ before the beginning of the experiment. One liter of ruminal fluid was taken from the cow with a vacuum pump 30 min before the morning meal and strained through a metal sieve (1.6-mm mesh). Rumen fluid was quickly transferred to the laboratory in anaerobic conditions at $39^{\circ} \mathrm{C}$.

Erlenmeyer flasks, containing $52 \mathrm{mg}$ of TGLA or HTGLA, $50 \mathrm{mg}$ of FLA or HFLA, or $50 \mathrm{mg}$ of FLA together with $5 \mathrm{mg}$ of $13 \mathrm{HPOD}$, HEX, or T2D, and a fermentative substrate ( $1 \mathrm{~g}$ of 2 -mm-ground meadow hay, $0.2 \mathrm{~g}$ of $1-\mathrm{mm}$-ground soybean meal, and $0.25 \mathrm{~g}$ of 1-mm-ground corn grain), were filled with $40 \mathrm{~mL}$ of rumen fluid and $40 \mathrm{~mL}$ of bicarbonate buffer gassed with $\mathrm{CO}_{2}$ and heated to $39^{\circ} \mathrm{C}\left(\mathrm{pH}=7 ; \mathrm{Na}_{2} \mathrm{HPO}_{4} \cdot 12 \mathrm{H}_{2} \mathrm{O} 19.5\right.$ $\mathrm{g} / \mathrm{L}, \mathrm{NaHCO}_{3} 9.24 \mathrm{~g} / \mathrm{L}, \mathrm{NaCl} 0.705 \mathrm{~g} / \mathrm{L}, \mathrm{KCl} 0.675 \mathrm{~g} / \mathrm{L}$, $\mathrm{CaCl}_{2} \cdot 2 \mathrm{H}_{2} \mathrm{O} 0.108 \mathrm{~g} / \mathrm{L}$, and $\mathrm{MgSO}_{4} \cdot 7 \mathrm{H}_{2} \mathrm{O} 0.180 \mathrm{~g} / \mathrm{L}$ ). The filled flasks were gassed with $\mathrm{CO}_{2}$ and placed in the water bath at $39^{\circ} \mathrm{C}$. The flasks were then closed with a rubber bung through which a plastic tube led into the water to vent fermentation gas without ingress of oxygen. Flasks were stirred at $130 \mathrm{rpm}$ and kept out of the light for 6 or $24 \mathrm{~h}$. At the end of incubation, fermentations were stopped by placing the flasks in iced water. One replicate for each treatment and incubation duration was incubated during each of the $6 \mathrm{~d}$ of culture, regrouped in 2 wk (i.e., a total of 6 replicates per treatment for 6 -h and for 24-h incubations). Each day, 2 blanks, without fat or any oxidative product and not incubated, were prepared to represent the initial state of the media and placed immediately in iced water. In incubated flasks and blanks, $\mathrm{pH}$ was measured and $2 \times 1 \mathrm{~mL}$ aliquots were sampled in Eppendorf tubes for bacterial community analysis. The contents of the flasks and Eppendorf tubes were then immediately frozen. Samples were freeze-dried (Virtis Freezemobile 25; Virtis, Gardiner, NY) and weighed. Flask contents were ground and homogenized in a ball mill (Dangoumau, Prolabo, Nogent-sur-Marne, France) and kept at $-18^{\circ} \mathrm{C}$ for later analysis of FA. Eppendorf tubes were kept at $-80^{\circ} \mathrm{C}$ until analysis.

Experiment 2. Ruminal cultures were prepared as for experiment 1, with some differences. Rumen fluid was collected and mixed from 2 lactating dairy cows fed a corn silage-based diet (20 $\mathrm{kg}$ of corn silage, $3 \mathrm{~kg}$ of meadow hay, $1.6 \mathrm{~kg}$ of soybean meal, and $0.2 \mathrm{~kg}$ of mineral vitamin mixture, as fed, per day). The cows were adapted to this diet for $16 \mathrm{~d}$ before the beginning of the experiment. Six different aldehydes were chosen as the oxidation products, taking into account their chain length and degree of unsaturation: pentanal (PEN, purity $\geq 97 \%$ ), HEX (purity $\geq 97 \%$ ), heptanal (HEP, purity $\geq 95 \%$ ), nonanal (NON, purity $\geq 95 \%$ ), $\mathrm{T} 2 \mathrm{D}$ (purity $\geq 95 \%$ ), and $\mathrm{T} 2 \mathrm{~T} 4 \mathrm{D}$ (purity $\geq 85 \%$ ), all of commercial origin (Sigma Co.). Ten milligrams of 1 aldehyde was added to the cultures along with 80 mg of pure cis-9,trans-11-C18:2, and a fermentative substrate $(2 \mathrm{~g}$ of 2 -mm-ground meadow hay, $0.4 \mathrm{~g}$ of 1 -mm-ground soybean meal, and $0.5 \mathrm{~g}$ of 1 -mm-ground corn grain). Then, $80 \mathrm{~mL}$ of rumen fluid and $80 \mathrm{~mL}$ of bicarbonate buffer were added to each flask. Two replicates of each treatment were incubated for $5 \mathrm{~h}$, to give priority to CLA concentrations, during each of the $3 \mathrm{~d}$ of culture, regrouped in $1 \mathrm{wk}$ (i.e., a total of 6 replicates per treatment). Each day, 2 blanks, without fat and not incubated, were prepared to represent the initial state of the media. Because the main objective of this experiment was to investigate the effects of chain length and degree of unsaturation of aldehydes, no control without added aldehydes was incubated. At the end of the incubation, fermentations were stopped by placing the flasks into iced water, $\mathrm{pH}$ was measured, and samples were prepared and kept as for experiment 1 for bacterial and FA analysis.

Experiment 3. To explore the effect of lipid oxidative compounds on the 3 reactions of cis-9, cis-12-C18:2 $\mathrm{BH}, 4$ substrates were used: pure cis-9, cis-12-C18:2 for studying isomerization, cis-9,trans-11-CLA and trans10,cis-12-CLA (for both, purity $\geq 98 \%$, Cayman Chem- 
ical, Ann Arbor, MI) for studying the first reduction and trans-11-C18:1 (purity $\geq 99 \%$, Sigma Co.) for the last reduction. No incubation with trans-10-C18:1 was performed because no commercial standard is available for trans-10-C18:1. Oxidative products tested were the hydroperoxides 13HPOD and 9HPOD (for both, purity $\geq 98 \%$, Cayman Chemical) and the 2 main aldehydes of cis-9,cis-12-C18:2 oxidation, HEX and T2T4D. Their effects were assessed through the quantity of reaction products after a 1-h incubation with inactivated rumen fluid.

The lactating dairy cow from which the rumen fluid was taken was fed a corn silage-based diet $(36 \mathrm{~kg}$ of corn silage, $2 \mathrm{~kg}$ of hay, $10 \mathrm{~kg}$ of a mixture of concentrates, and $0.2 \mathrm{~kg}$ of mineral vitamin mixture, as fed, per day). The adaptation period was $4 \mathrm{wk}$. The procedure for rumen fluid collection and transportation was the same as in the previous 2 experiments. In the laboratory, 200 mg of chloramphenicol was immediately added to 200 $\mathrm{mL}$ of rumen fluid in a flask and the flask was gassed with $\mathrm{CO}_{2}$, closed, and stirred. After 5 min of continuous stirring, the flask was put in an oven at $39^{\circ} \mathrm{C}$ for $5 \mathrm{~h}$ to completely stop the bacterial activity (Allison et al., 1962), resulting in an enzymatic solution.

In $200-\mathrm{mL}$ tubes, $0.1 \mathrm{mg}$ of one oxidative product (except in control tubes) and $1 \mathrm{mg}$ of one of the FA were added, investigating all possible combinations: no oxidative product or 1 of 4 oxidative products $\times 4 \mathrm{FA}$. To precisely dose the products at such low quantities, HEX, T2T4D, and FA were first dissolved in hexane and HPOD was dissolved in ethanol. Once the appropriate volume was introduced in tube, the solvent was eliminated at $50^{\circ} \mathrm{C}$ under nitrogen. Thereafter, $1 \mathrm{~mL}$ of enzymatic solution and $1 \mathrm{~mL}$ of bicarbonate buffer $\left(\mathrm{pH}=7 ; \mathrm{Na}_{2} \mathrm{HPO}_{4} \cdot 12 \mathrm{H}_{2} \mathrm{O} 19.5 \mathrm{~g} / \mathrm{L}\right.$ and $\mathrm{NaHCO}_{3} 9.24$ $\mathrm{g} / \mathrm{L}$ ) was added to each tube. The tubes were filled with $\mathrm{CO}_{2}$ and a magnetic stirrer was added to each tube before closing them firmly. Thereafter, these tubes were incubated and stirred for $1 \mathrm{~h}$ in a water bath at $39^{\circ} \mathrm{C}$. Moreover, for each of the $4 \mathrm{FA}$ used in this study, one tube was frozen without incubation to measure the initial status of the medium with enzymatic solution. After incubation, the tubes were frozen at $-20^{\circ} \mathrm{C}$ and freeze-dried.

\section{Chemical Analyses}

$\boldsymbol{F A}$ Analysis. The FA of feed and in vitro substrate ingredients, TGLA, HTGLA, FLA, HFLA, and 13HPOD, control flasks, and incubated media were extracted and methylated in situ using the procedure of Park and Goins (1994), except that the solution of $14 \%$ boron trifluoride in methanol was replaced by a solution of methanol-acetylchloride (10:1). Nonadeca- noic acid (C19:0) was used as the internal standard at a dose of $0.8 \mathrm{mg}$. The FA methyl esters were then quantified by gas chromatography (Agilent 6890N, Network GC System, equipped with a model 7683 auto injector, Agilent Technologies, Palo Alto, CA) using a fused-silica capillary column $(100 \mathrm{~m} \times 0.25 \mathrm{~mm}$ i.d., $0.20-\mu \mathrm{m}$ film thickness, CPSil88,Varian, Middelburg, the Netherlands), as described in Zened et al. (2011). Peaks were identified and quantified by comparison with commercial standards (Sigma Co.), except C18:1 (other than trans-9-C18:1, trans-11-C18:1, and cis9-C18:1), which were identified by order of elution. Chromatograms were integrated using the Peak Simple software (Peak Simple Data System, version 3.29, SRI, Torrance, CA).

Lipid Oxidation Product Analysis. The analyses were performed as described by Kaleem et al. (2013). For the TAG polymer assay, the NF T60-268 official method was used (AFNOR, 2000), except for the detector. The analysis was performed by HPLC with an P680 HPLC pump (Dionex, Voisins le Bretonneux, France) coupled with an evaporative light-scattering detector (PL-ELS 2100, Polymer Laboratories, Church Stretton, UK) equipped with a size-exclusion PLgel column (particle size $5 \mu \mathrm{m}$, pore size $300 \AA, 300 \times$ $7.5 \mathrm{~mm}$ i.d, Polymer Laboratories). The mobile phase was tetrahydrofuran. The injected volume was $20 \mu \mathrm{L}$, the column oven temperature was set at $30^{\circ} \mathrm{C}$, and the mobile phase flow rate was $1 \mathrm{~mL} / \mathrm{min}$. The conditions for evaporative light scattering detection were $1 \mathrm{~mL} /$ min for nitrogen flow rate, $50^{\circ} \mathrm{C}$ for nebulization temperature, and $75^{\circ} \mathrm{C}$ for evaporation temperature.

Analysis of hydroperoxides and hydroxyacids was performed according to the HPLC method of Browne and Armstrong (2000), after saponification of lipids for TGLA and HTGLA: $100 \mathrm{mg}$ of sample plus $2 \mathrm{~mL}$ of 1 $M$ potassium hydroxide (prepared in $95 \%$ ethanol) were kept for $16 \mathrm{~h}$ under continuous stirring at $20^{\circ} \mathrm{C}$. Then, $5 \mathrm{~mL}$ of ultrapure water and $10 \mathrm{~mL}$ of hexane were added and homogenized by vigorous manual stirring. The upper organic phase was eliminated as it contained the nonsaponified molecules, and the alcoholic phase was acidified using $5 \mathrm{~mL}$ of $6 \mathrm{~N} \mathrm{HCl}$. Afterward, this phase was washed 3 times with $10 \mathrm{~mL}$ of hexane and filtered with a phase separator silicone-treated filter paper (1PS, Whatman Inc., Buckinghamshire, UK). Hexane was evaporated under vacuum at 35 to $40^{\circ} \mathrm{C}$. The residue was weighed and diluted with ethanol to obtain $10 \mathrm{mg}$ of residue per $\mathrm{mL}$ of ethanol; FLA, HFLA, and 13HPOD were diluted directly in ethanol in the same proportions. The analysis was performed on an automated HPLC-UV system using a P680 HPLC pump and diode array detection at $320 \mathrm{~nm}$ (Agilent Technologies). The column used for separation was an 
Table 1. Oligonucleotide sequences used for PCR capillary electrophoresis single-strand conformation polymorphism (CE-SSCP) and real-time PCR

\begin{tabular}{lllll}
\hline Group & Direction & Position & Oligonucleotide sequence $\left(5^{\prime}-3^{\prime}\right)$ & Reference \\
\hline PCR CE-SSCP Bacterial fingerprint & Forward & $329-348$ & ACGGTCCAGACTCCTACGGG & Delbès et al. (2000) \\
& Reverse & $515-532$ & FAM-TTACCGCGGCTGCTGGCAC & Zumstein et al. (2000) \\
Real-time PCR All Bacteria & Forward & $338-357$ & ACTCCTACGGGAGGCAGCAG & Fierer et al. (2005) \\
& Reverse & $518-534$ & ATTACCGCGGCTGCTGG & Fierer et al. (2005) \\
\hline
\end{tabular}

Uptisphere C18 ODB (particle size $3 \mu \mathrm{m}, 15 \times 0.46 \mathrm{~cm}$ i.d, Interchim, Montluçon, France). The mobile phase was a mixture of $1 \mathrm{~g} / \mathrm{L}$ acetic acid, acetonitrile, and tetrahydrofuran (52:30:18, vol/vol/vol). The injected volume was $20 \mu \mathrm{L}$ of the ethanol solution. The oven temperature of the column was set at $40^{\circ} \mathrm{C}$. The mobile phase flow rate was $1 \mathrm{~mL} / \mathrm{min}$. Peaks were identified and quantified by comparison with commercial standards (Interchim), focusing on products from cis-9, cis12-C18:2 oxidation, 13HPOD, and 9HPOD, and their respective hydroxyacids (13HOA and 9HOA).

Aldehyde analysis was performed according to the method of Li et al. (2005): $75 \mathrm{mg}$ of extracted oil was mixed with $10 \mathrm{~mL}$ of hexane, and then $1 \mu \mathrm{L}$ was injected into a gas chromatograph (Agilent 7890A, GC System, equipped with a model 7683 auto injector, Agilent Technologies) using a capillary column (30 m $\times 0.53 \mathrm{~mm}$ i.d., $0.5-\mu \mathrm{m}$ film thickness, DB-5, Agilent Technologies). For analysis, the flame-ionization detector temperature was maintained at $280^{\circ} \mathrm{C}$ and the injector at $280^{\circ} \mathrm{C}$; the split ratio was $1: 5$. Nitrogen was used as the carrier gas with a constant flow of $4 \mathrm{~mL} /$ min. The initial oven temperature was $60^{\circ} \mathrm{C}$, and was increased by $2^{\circ} \mathrm{C} / \mathrm{min}$ to $70^{\circ} \mathrm{C}$, then increased by $10^{\circ} \mathrm{C} /$ min to $250^{\circ} \mathrm{C}$ and held for 1 min. Peaks were identified and quantified by comparison with commercial standards (Sigma Co.).

Chromatograms for TAG polymers, hydroperoxides or hydroxyacids, and aldehydes were integrated using the Chromeleon chromatography data system software (version 6.60, Dionex).

\section{Microbiological Analyses}

DNA Extraction. Total DNA from $1 \mathrm{~mL}$ of freezedried ruminal sample was extracted and purified using the QIAamps DNA Stool Mini kit (Qiagen Ltd., West Sussex, UK) according to the manufacturer's documentation with a previous bead-beating step in a FastPrep Instrument (MP Biomedicals, Illkirch, France).

Total Bacterial Community Abundance. Total numbers of bacteria in the cultures was estimated by quantitative PCR, as described in Combes et al. (2011). Assays were performed using the ABI Prism 7900HT sequence detection system (Applied Biosystems, Carls- bad, CA) in optical-grade 384-well plates in a final volume of $10 \mu \mathrm{L}$. The SYBR Green assay reaction mixture contained template DNA, a specific primer set at 100 n $M$ (Table 1), and $1 \times$ Power SYBR Green PCR Master Mix (Applied Biosystems). A dissociation curve was added to SYBR Green assays to check the specificity of the amplification. Then, the results were compared with a standard curve to obtain the number of target copies in the sample. The standard DNA curves were generated by amplification of the serial 10-fold dilutions of a reference plasmid containing the target $16 \mathrm{~S}$ rRNA gene (accession no. EF445235 Prevotella bryantii).

Structure and Diversity of the Bacterial Community. Bacterial community analysis was performed as described by Michelland et al. (2009). The V3 region of the $16 \mathrm{~S}$ rRNA genes of bacterial species, corresponding to a 205-bp fragment in Escherichia coli, was used as a diversity marker by performing PCR (Table1). Bacterial communities were spread out in about 1,700 scans. Capillary electrophoresis single-strand conformation polymorphism (CE-SSCP) profiles were aligned and normalized and the diversity index was estimated using StatFingerprints program version 1.3 (Michelland et al., 2009). The Simpson index, which is an estimate of bacterial population diversity, was calculated according to Michelland et al. (2009) and the formula $-\log _{10} \Sigma(a i)^{2}$, where ai is the relative area under the ith peak detected in the CE-SSCP profile (Rosenzweig, 1995).

Calculations. The FA data were expressed as quantities of FA produced or disappeared, to directly assess $\mathrm{BH}$ capacity of bacteria. For each FA, production or disappearance was calculated as amount in incubated flask - (amount in blank + amount from added fat).

The rates $(\mathbf{v})$ and efficiencies $(\mathbf{E})$ of the cis9, cis12C18:2 isomerization (v1, E1), CLA reduction (v2, E2), and trans-C18:1 reduction (v3, E3) were calculated as previously described by Troegeler-Meynadier et al. (2006a):

$$
\begin{gathered}
\mathrm{v} 1=([\mathrm{C} 18: 2] \mathrm{b}-[\mathrm{C} 18: 2] \mathrm{e}) / \mathrm{t}, \\
\mathrm{E} 1=([\mathrm{C} 18: 2] \mathrm{b}-[\mathrm{C} 18: 2] \mathrm{e}) /[\mathrm{C} 18: 2] \mathrm{b},
\end{gathered}
$$

where $[\mathrm{C} 18: 2] \mathrm{b}$ and $[\mathrm{C} 18: 2] \mathrm{e}$ represent the concentrations $(\mathrm{mg} / \mathrm{L})$ of cis-9,cis-12-C18:2 at the beginning 
and at the end of incubation, respectively, and t is the incubation time;

$$
\begin{gathered}
\mathrm{v} 2=([\mathrm{C} 18: 2] \mathrm{b}-[\mathrm{C} 18: 2] \mathrm{e}+[\mathrm{CLA}] \mathrm{b}-[\mathrm{CLA}] \mathrm{e}) / \mathrm{t}, \\
\mathrm{E} 2=([\mathrm{C} 18: 2] \mathrm{b}-[\mathrm{C} 18: 2] \mathrm{e}+[\mathrm{CLA}] \mathrm{b}-[\mathrm{CLA}] \mathrm{e}) / \\
([\mathrm{C} 18: 2] \mathrm{b}-[\mathrm{C} 18: 2] \mathrm{e}+[\mathrm{CLA}] \mathrm{b}),
\end{gathered}
$$

where $[\mathrm{CLA}] \mathrm{b}$ and $[\mathrm{CLA}] \mathrm{e}$ represent the concentration $(\mathrm{mg} / \mathrm{L})$ of total CLA isomers measured at the beginning and at the end of the incubation, respectively; and

$$
\begin{aligned}
& \mathrm{v} 3=([\mathrm{C} 18: 2] \mathrm{b}-[\mathrm{C} 18: 2] \mathrm{e}+[\mathrm{CLA}] \mathrm{b}-[\mathrm{CLA}] \mathrm{e} \\
& +[\text { trans-C18:1]b }-[\text { trans-C18:1]e)/t, } \\
& \mathrm{E} 3=([\mathrm{C} 18: 2] \mathrm{b}-[\mathrm{C} 18: 2] \mathrm{e}+[\mathrm{CLA}] \mathrm{b}-[\mathrm{CLA}] \mathrm{e} \\
& +[\text { trans-C18:1]b }-[\text { trans-C18:1]e)/([C18:2]b } \\
& -[\mathrm{C} 18: 2 \mathrm{n}-6] \mathrm{e}+[\mathrm{CLA}] \mathrm{b}-[\mathrm{CLA}] \mathrm{e}+[\text { trans-C18:1]b), }
\end{aligned}
$$

where $[$ trans-C18:1]b and [trans-C18:1]e represent the concentration $(\mathrm{mg} / \mathrm{L})$ of total trans-C18:1 isomers measured at the beginning and at the end of the incubation.

Data Analysis. Fatty acid production or disappearance, rates and efficiencies of the $\mathrm{BH}$ reactions, and quantitative PCR and diversity indices of the bacterial community were analyzed using the general linear model of SYSTAT (version 9, SPSS Inc., Chicago, IL) and are reported as mean values with standard errors of the mean. Several models were used.

Experiment 1 had 2 objectives: testing the effects of oxypolymers on $\mathrm{BH}$ of cis-9,cis-12-C18:2 as TAG, and testing the effects of oxidative products on $\mathrm{BH}$ of free cis-9,cis-12-C18:2, so we used different statistical analyses:

Model 1 analyzed the effects of TAG polymers on BH in experiment 1 :

variable $=$ mean + "day of incubation" effect

+ "duration of incubation" effect + "heating" effect

+ interaction "heating $\times$ incubation duration" $+\varepsilon,[1]$

where $\varepsilon$ is the residual error.

Model 2 compared the effects of FLA, HFLA, 13HPOD, HEX, and T2D on BH in experiment 1, analyzing 6 - and 24 -h incubations separately:

$$
\begin{aligned}
\text { variable }= & \text { mean }+ \text { "day of incubation" effect } \\
& + \text { "treatment" effect }+\varepsilon .
\end{aligned}
$$

Model 3 compared the effects of TGLA, HTGLA, FLA, HFLA, 13HPOD, HEX, and T2D on bacterial number and diversity in experiment 1 :

$$
\begin{aligned}
& \text { variable }=\text { mean }+ \text { "day of incubation" effect } \\
& + \text { "treatment" effect + "duration of incubation" } \\
& \text { effect + interaction "treatment } \\
& \quad \times \text { incubation duration" }+\varepsilon .
\end{aligned}
$$

In experiment 2, the effects of the nature of aldehyde on $\mathrm{BH}$ and on bacterial number and diversity were analyzed with the model

$$
\begin{gathered}
\text { variable }=\text { mean }+ \text { "day of incubation" effect } \\
+ \text { "nature of aldehyde" effect }+\varepsilon .
\end{gathered}
$$

In experiment 3, the effect of the hydroperoxides (13HPOD and 9HPOD) and aldehydes (HEX and T2T4D) on enzymatic $\mathrm{BH}$ reactions was analyzed with the model

$$
\begin{gathered}
\text { variable }=\text { mean }+ \text { "day of incubation" effect } \\
+ \text { "oxidative products or none" effect }+\varepsilon .
\end{gathered}
$$

When the treatment effects were significant, a Tukey test was used for pairwise comparisons.

In experiment 2, linear correlations between individual FA balances and chain length and degree of unsaturation of aldehydes were computed.

To compare the structure of the bacterial communities, the pairwise Euclidean distances of the CE-SSCP profiles were used. Analysis of similarity (ANOSIM) was performed on the distance matrix using 10,000 Monte Carlo permutations. Global ANOSIM was performed to test the fixed effects of treatment (all data except TGLA and HTGLA, experiment 1) or of aldehydes (experiment 2). The ANOSIM R-value indicates the extent to which the groups differed and lies between 0 (no separation) and 1 (well-separated groups). When a fixed effect was significant, an iterative Mann-Whitney test was carried out on the 1,700 scans of the CE-SSCP profiles to estimate the percentage of the population that differed between 2 factors. Significance was set at $P \leq 0.05$.

\section{RESULTS}

For experiments 1 and 2, $\mathrm{pH}$ was not affected by addition of oxidative products. In experiment 1 , initial $\mathrm{pH}$ was 7.0, and final $\mathrm{pH}$ was 6.8 and 6.6 after 6 - and 
Table 2. Quantities of cis-9,cis-12-C18:2 and oxidative products added to the different cultures (per flask, experiment 1)

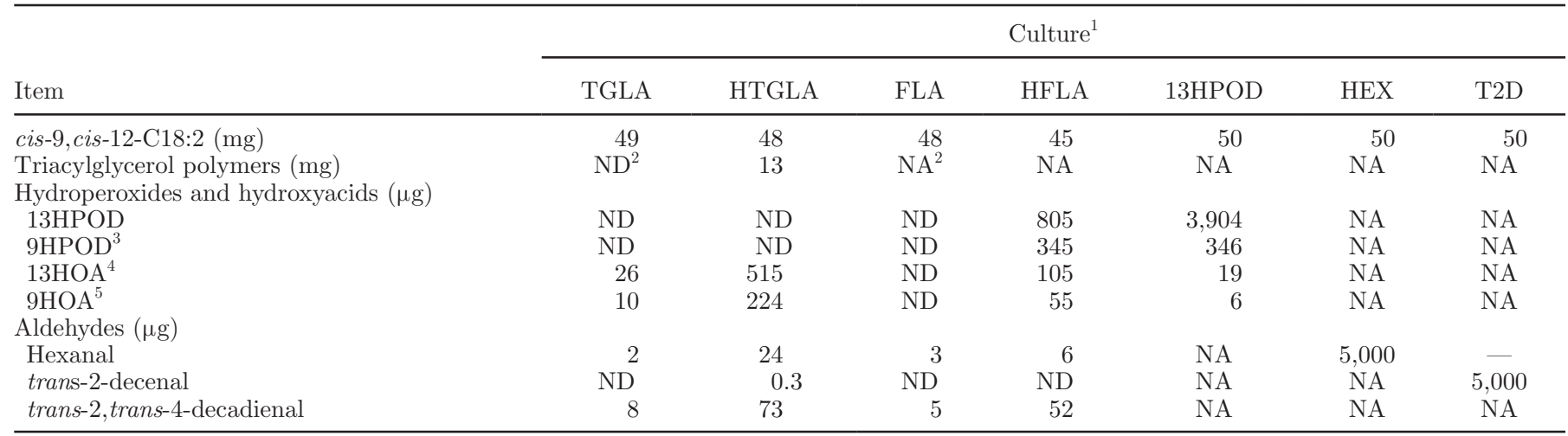

${ }^{1}$ TGLA $=$ pure triacylglycerol of cis-9,cis-12-C18:2; HTGLA = heated TGLA $\left(150^{\circ} \mathrm{C}\right.$ for $\left.6 \mathrm{~h}\right) ; \mathrm{FLA}=$ pure cis-9, cis-12-C18:2; HFLA $=$ heated FLA $\left(150^{\circ} \mathrm{C}\right.$ for $\left.6 \mathrm{~h}\right) ; 13 \mathrm{HPOD}=13-\mathrm{OOH}$ cis-9,trans-11-C18:2; HEX = pure hexanal; T2D = pure trans-2-decenal.

${ }^{2} \mathrm{ND}=$ not detected; $\mathrm{NA}=$ not analyzed.

${ }^{3} 9 \mathrm{HPOD}=9-\mathrm{OOH}$ trans-10, cis-12-C18:2. ${ }^{4} 13 \mathrm{HOA}=13-\mathrm{OH}$ cis-9, trans-11-C18:2

${ }^{5} 9 \mathrm{HOA}=9-\mathrm{OH}$ trans-10, cis-12-C18:2.

24-h incubations, respectively; in experiment $2, \mathrm{pH}$ was 7.0 and 6.8 after 6 - and 24-h incubations, respectively.

\section{Oxidative Products of Heated Fat Sources}

The thermal treatment of TGLA was sufficient to generate TAG polymers, which represented $27 \%$ of added fat in HTGLA incubations (Table 2). It produced small amounts of aldehydes and large amounts of hydroxyacids, but hydroperoxides were not detectable. Conversely, heating FLA resulted in a high production of hydroperoxides and a low production of hydroxyacids and aldehydes. Among hydroperoxides and hydroxyacids, $13 \mathrm{OOH}$ or $13 \mathrm{OH}$ isomers were the predominant forms. The main aldehyde obtained by heating either TGLA or FLA was T2T4D.

\section{Effect of TAG on BH}

Heating TAG had no effect on cis-9,cis-12-C18:2 disappearance regardless of incubation duration; therefore, the 2 incubation durations were combined (Figure 1). Nevertheless, some differences were observed on BH intermediates: heating of TAG significantly $(P<$ 0.01) decreased the production of CLA, trans-C18:1, and C18:0 (Figure 2). This decrease was less important for trans-10 isomers $(-41 \%)$ than for trans-11 isomers $(-86 \%)$.

\section{Comparative Effects of cis-9,cis-12-C18:2 Heating and Addition of Hydroperoxide or Aldehydes on $\mathrm{BH}$}

In experiment 1, compared with FLA, HFLA led to a decrease of cis-9,cis-12-C18:2 disappearance and of CLA and trans-C18:1 production, regardless of incuba- tion duration, and a decrease in C18:0 production for 24-h incubations (Tables 3 and 4). The BH intermediate isomers whose production was significantly decreased by heating were trans-11-C18:1 and cis-9,trans-11-CLA. Conversely, 13HPOD, HEX, and T2D treatments did not affect cis-9,cis-12-C18:2 disappearance or production of total trans-C18:1 or CLA. Nevertheless, some differences were observed in distribution of $\mathrm{BH}$ intermediate isomers. In particular, 13HPOD resulted in the highest trans-10-C18:1 production for 6-h incubations, and, as observed with HFLA, decreased trans-11 isomer production during 24-h incubations. Both aldehydes, HEX and T2D, had little effect on the production of $\mathrm{BH}$ products, but $\mathrm{T} 2 \mathrm{D}$ resulted in significantly higher

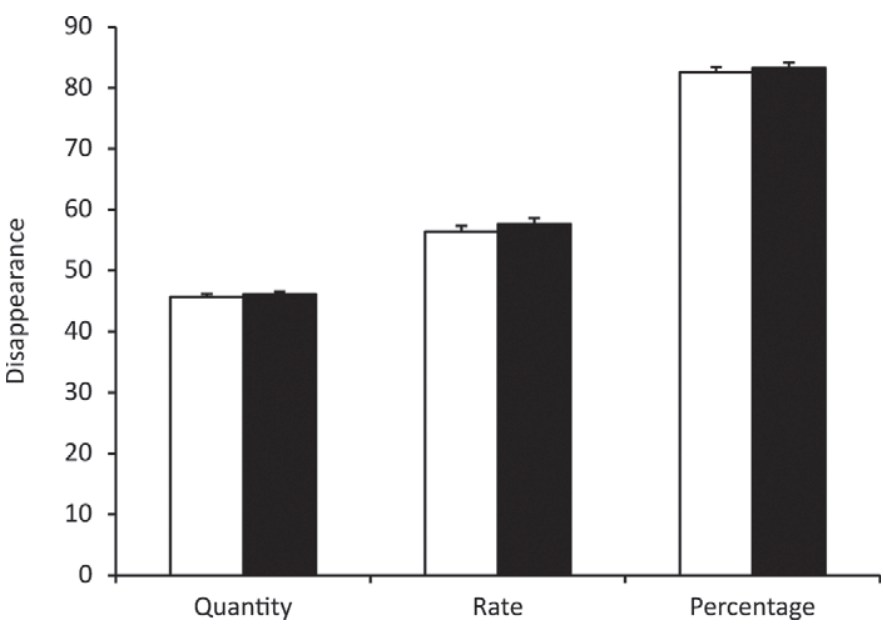

Figure 1. Quantity (mg/flask), rate (mg/L per hour), and percentage (\%) of cis-9,cis-12-C18:2 disappearance when incubated with rumen fluid as heated $(\square)$ or nonheated $(\square)$ triacylglycerols, combining values from 6- and 24-h incubations. Error bars = SEM. 


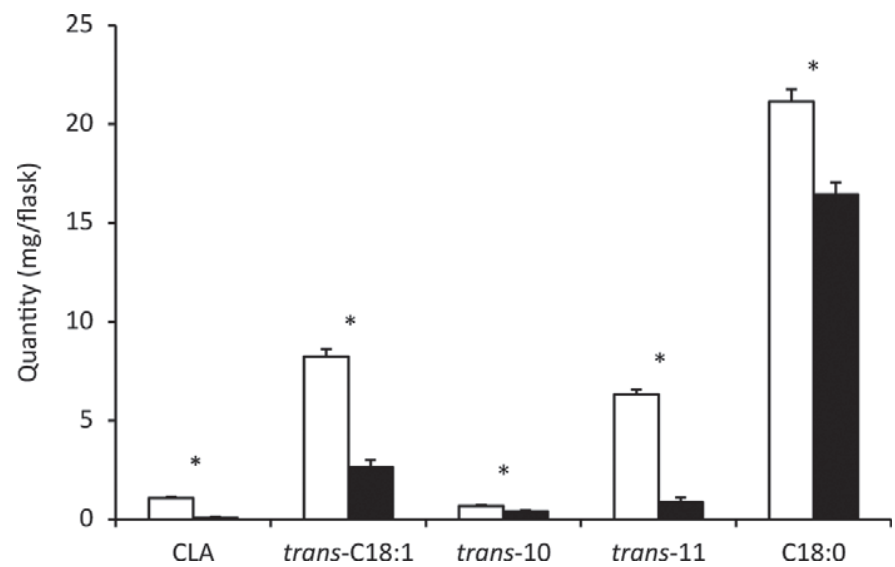

Figure 2. Quantities (mg/flask) of total conjugated linoleic acid (CLA), total trans-C18:1, trans-10 isomers (trans-10,cis-12-CLA + trans-10-C18:1), trans-11 isomers (cis-9,trans-11-CLA + trans9,trans-11-CLA + trans11-C18:1), and C18:0 produced from cis-9,cis12-C18:2 when incubated with rumen fluid as heated $(\mathbf{\square})$ or nonheated $(\square)$ triacylglycerols, combining values from 6- and 24-h incubations. Error bars $=\mathrm{SEM} ; * P<0.01$. trans-10 isomer production than did HEX for 6-h incubations. Moreover, 13HPOD increased cis-12-C18:1 production in 6- and 24-h incubations and T2D only in 6-h incubations compared with FLA, with HFLA and HEX resulting in intermediate values.

Compared with FLA, HFLA decreased the rate and efficiency of isomerization, regardless of incubation duration (Tables 3 and 4). Rates of both reductions were also significantly decreased by heating, but their efficiencies were not affected. Other treatments (13HPOD, HEX, and T2D) did not modify BH kinetic parameters compared with FLA.

\section{Effects of Aldehyde Chain Length and Degree of Unsaturation on $\mathrm{BH}$}

In experiment 2 , the different assayed aldehydes resulted in similar disappearances of cis-9, cis-12-C18:2 (Table 5). No effect was noticed on trans-C18:1 produc-

Table 3. Comparison of heating linoleic acid or adding oxidation products on production (positive values), disappearance (negative values) of FA (mg/flask), rates (v, mg/L per hour), and efficiencies (E, \%) of the 3 reactions of cis-9, cis-12-C18:2 biohydrogenation after a 6-h incubation with ruminal fluid, focusing on its biohydrogenation products (experiment 1)

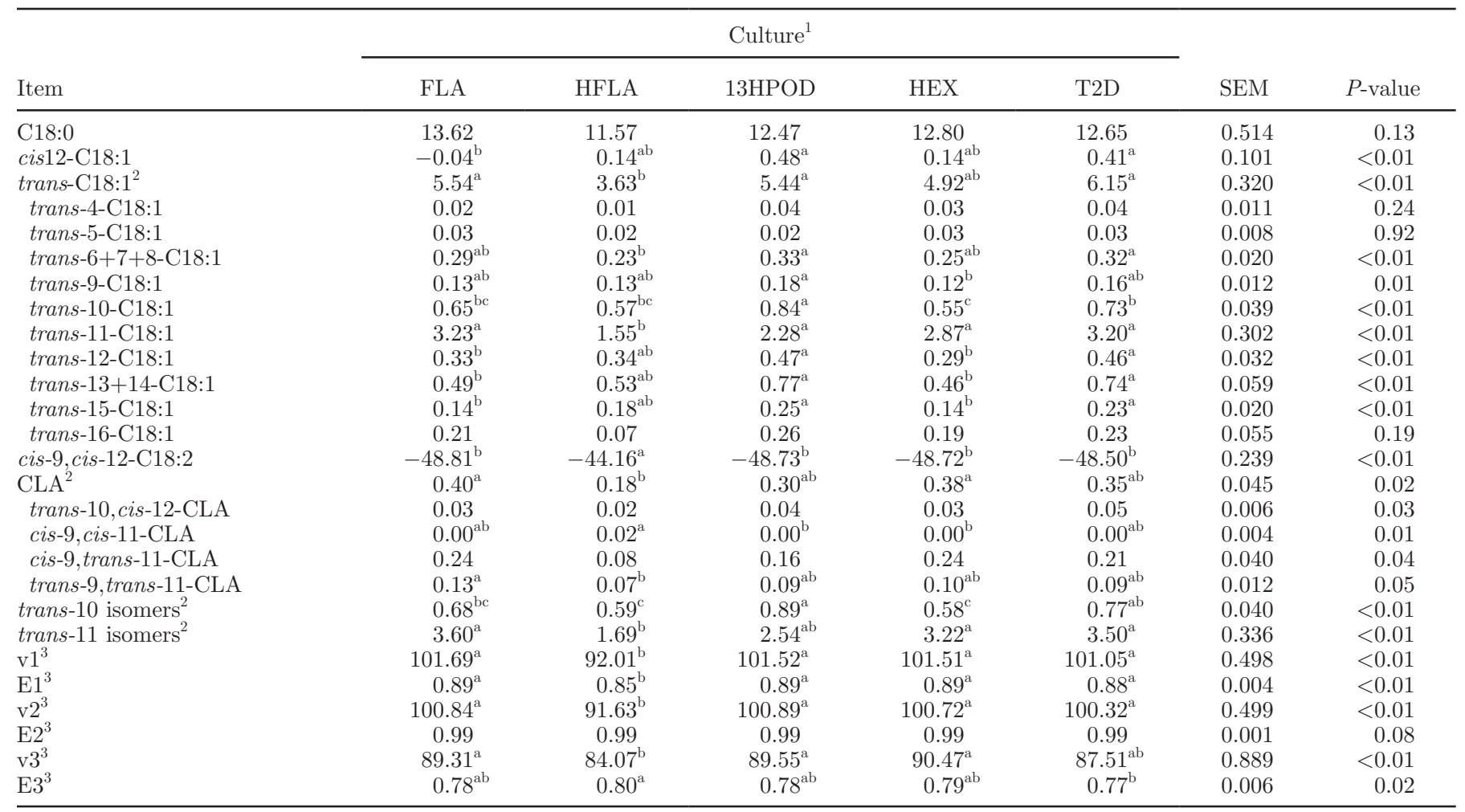

${ }^{\mathrm{a}-\mathrm{c}}$ Means in the same row with different superscripts differ significantly $(P<0.05)$.

${ }^{1} \mathrm{FLA}=$ pure $c i s-9$, cis-12-C18:2; HFLA = heated FLA $\left(150^{\circ} \mathrm{C}\right.$ for $\left.6 \mathrm{~h}\right) ; 13 \mathrm{HPOD}=13-\mathrm{OOH}$ cis-9,trans-11-C18:2; HEX = pure hexanal; T2D $=$ pure trans-2-decenal.

${ }^{2}$ trans-C18:1 and conjugated linoleic acid (CLA) are the sums of the respective assayed isomers; trans-10 isomers $=$ trans-10, cis-12-CLA + trans10-C18:1; trans-11 isomers $=$ cis-9, trans-11-CLA + trans-9, trans-11-CLA + trans-11-C18:1.

${ }^{3} \mathrm{v} 1$ and E1 refer to the isomerization of cis-9,cis-12-C18:2 to CLA; v2 and E2 refer to the reduction of CLA to trans-C18:1 isomers; v3 and E3 refer to the reduction of trans-C18:1 to C18:0. 
Table 4. Comparison of heating linoleic acid or adding oxidation products on production (positive values), disappearance (negative values) of FA (mg/flask), rates (v, mg/L per hour), and efficiencies (E, \%) of the 3 reactions of cis-9,cis-12-C18:2 biohydrogenation after a 24-h incubation with ruminal fluid, focusing on its biohydrogenation products (experiment 1 )

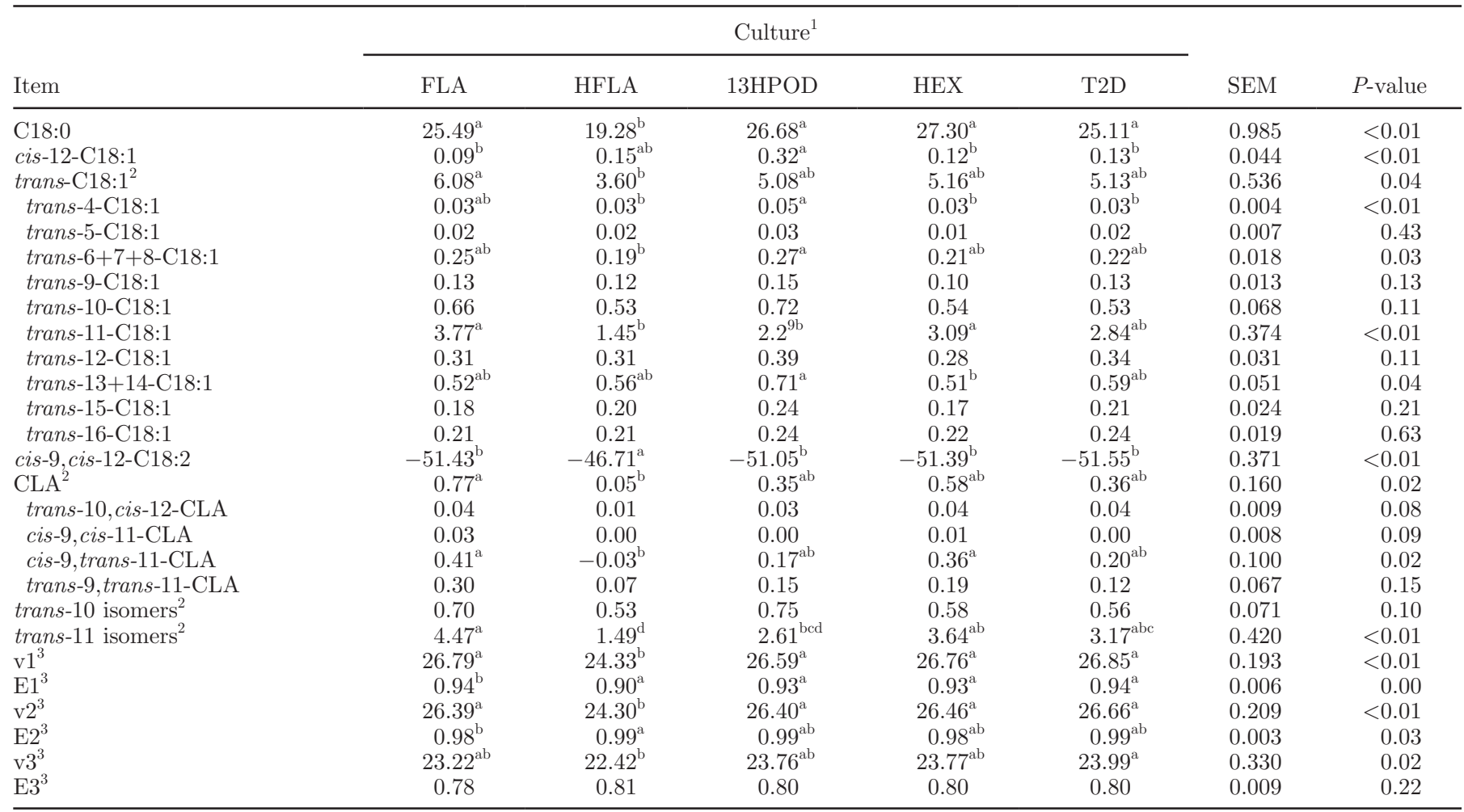

${ }^{\mathrm{a}-\mathrm{d}}$ Means in the same row with different superscripts differ significantly $(P<0.05)$.

${ }^{1} \mathrm{FLA}=$ pure cis-9, cis-12-C18:2; HFLA = heated FLA $\left(150^{\circ} \mathrm{C}\right.$ for $\left.6 \mathrm{~h}\right) ; 13 \mathrm{HPOD}=13$-OOH cis-9, trans-11-C18:2; HEX = pure hexanal; T2D $=$ pure trans-2-decenal.

${ }^{2}$ trans-C18:1 and conjugated linoleic acid (CLA) are the sums of the respective assayed isomers; trans-10 isomers = trans-10, cis-12-CLA + trans10-C18:1; trans-11 isomers = cis-9, trans-11-CLA + trans-9, trans-11-CLA + trans-11-C18:1.

${ }^{3} \mathrm{v} 1$ and E1 refer to the isomerization of cis-9,cis-12-C18:2 to CLA; v2 and E2 refer to the reduction of CLA to trans-C18:1 isomers; v3 and E3 refer to the reduction of trans-C18:1 to C18:0.

tion, but CLA production was significantly decreased by NON. The highest value for trans-10, cis-12-CLA and trans-10-C18:1 production was obtained with HEP, and the highest value for cis-9,trans-11-CLA and trans-11-C18:1 production was obtained with T2D and T2T4D. However, differences were small and not always significant. We observed no significant relationship between individual FA balances and chain length or degree of unsaturation of aldehydes.

\section{Effects of Fat Heating and Addition of Aldehydes or Hydroperoxides on Ruminal Bacterial Population}

In experiments 1 and 2, fat heating and addition of oxidative products had no effect on ruminal bacterial density or diversity, resulting in values similar to those of blanks (Table 6). The bacterial community assessed by CE-SSCP was affected by 13HPOD addition to cultures in experiment 1 (Table 7), compared with FLA and HLA, with HEX and T2D being intermediate. It- erative tests showed that differences were large for 6 -h incubations but not for 24-h incubations; for example, the percentage difference was $27 \%$ between a bacterial community obtained from ruminal cultures with FLA and 13HPOD $(P<0.05)$ for 6 -h incubations and only $2 \%(P<0.05)$ for 24 -h incubations. In experiment 2 , ruminal bacterial density and diversity did not differ between aldehydes, and values obtained with aldehydes were similar to those obtained with blanks (Table 6). The bacterial community assessed by CE-SSCP did not differ according to aldehydes $(P>0.05$; results not shown).

\section{Effects of Aldehydes and Hydroperoxides on Enzymatic BH Reactions}

In experiment $3, \mathrm{BH}$ was almost complete as shown by $\mathrm{C} 18: 0$ being the major $\mathrm{BH}$ product. Nevertheless, some effects of added products could be noticed on isomerization (Table 8): $\Delta^{9}$-isomerization (producing 
Table 5. Comparison of effects of different aldehydes on production (positive values) or disappearance (negative values) of FA (mg/flask) after a 5-h incubation with ruminal fluid, focusing on cis-9, cis-12-C18:2 biohydrogenation products (experiment 2)

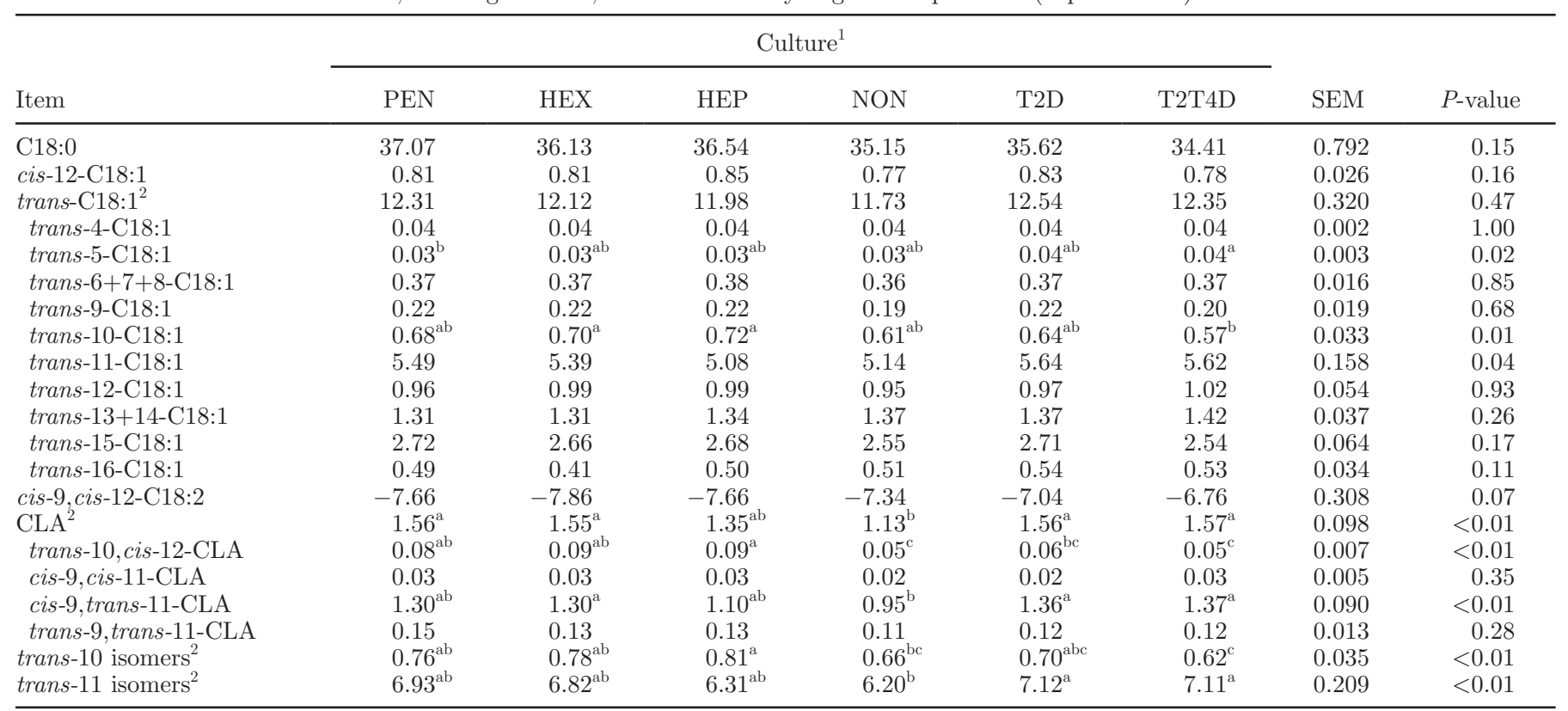

${ }^{\mathrm{a}-\mathrm{c}}$ Means in the same row with different superscripts differ significantly $(P<0.05)$.

${ }^{1} \mathrm{PEN}=$ pure pentanal; HEX $=$ pure hexanal; HEP $=$ pure heptanal; NON $=$ pure nonanal; T2D $=$ pure trans-2-decenal; T2T4D $=$ pure trans2,trans-4-decadienal.

${ }^{2}$ trans-C18:1 and conjugated linoleic acid (CLA) are the sums of the respective assayed isomers; trans-10 isomers $=$ trans-10, cis-12-CLA + trans10-C18:1; trans-11 isomers $=$ cis-9,trans-11-CLA + trans-9,trans-11-CLA + trans11-C18:1.

trans-10 isomers) was inhibited by $9 \mathrm{HPOD}$, and $\Delta^{12}$ isomerization (producing trans-11 isomers) was inhibited by both 9HPOD and 13HPOD. The first reduction was significantly but only slightly altered by oxidative products. The second reduction was not affected.

\section{DISCUSSION}

Polymers of TAG did not affect cis-9,cis-12-C18:2 disappearance, which suggests that TAG polymers have no effect on either lipolysis or cis-9, cis-12-C18:2 isomerization. This is consistent with the results of Tarvainen et al. (2010), who observed that oxidized TAG are hydrolyzed by the porcine lipase as efficiently as unoxidized molecules. Nevertheless, in HTGLA compared with TGLA incubations, a significant decrease in all $\mathrm{BH}$ products (CLA, trans-C18:1, and $\mathrm{C} 18: 0$ ) was observed, suggesting that the increase of oxidative products (Table 2) could have shifted cis-9, cis-12-C18:2

Table 6. Effects of heating fat and adding oxidative products on bacterial density (total bacteria quantitative PCR, no. of copies per mL of culture) and diversity (Simpson index) of bacterial community in experiments 1 and 2

\begin{tabular}{|c|c|c|c|c|c|c|c|c|c|c|}
\hline \multirow[b]{2}{*}{ Item } & \multicolumn{8}{|c|}{ Culture $^{1}$} & \multirow[b]{2}{*}{ SEM } & \multirow[b]{2}{*}{$P$-value } \\
\hline & $\begin{array}{c}\text { Nonincubated } \\
\text { blank }\end{array}$ & TGLA & HTGLA & FLA & HFLA & 13HPOD & HEX & $\mathrm{T} 2 \mathrm{D}$ & & \\
\hline \multicolumn{11}{|l|}{ Experiment 1} \\
\hline $\begin{array}{l}\text { Log (no. of copies } / \mathrm{mL} \\
\text { of culture) }\end{array}$ & 4.16 & 4.06 & 4.09 & 4.14 & 4.06 & 4.12 & 4.13 & 4.15 & 0.03 & 0.20 \\
\hline Simpson index & 7.39 & 8.22 & 7.75 & 7.92 & 7.71 & 7.68 & 8.10 & 8.05 & 0.22 & 0.40 \\
\hline \multirow{2}{*}{$\begin{array}{l}\text { Experiment } 2 \\
\text { Log (no. of copies } / \mathrm{mL} \\
\text { of culture) } \\
\text { Simpson index }\end{array}$} & 10.54 & 10.44 & 10.62 & 10.46 & 10.65 & 10.49 & 10.53 & & 0.11 & 0.69 \\
\hline & 8.09 & 8.87 & 8.73 & 8.81 & 8.98 & 8.83 & 8.46 & & 0.20 & 0.44 \\
\hline
\end{tabular}

${ }^{1}$ Nonincubated blanks reflect initial status and were not included in statistical analysis; TGLA = pure triacylglycerol of cis-9, cis-12-C18:2; HTGLA = heated TGLA $\left(150^{\circ} \mathrm{C}\right.$ for $\left.6 \mathrm{~h}\right) ; \mathrm{FLA}=$ pure cis-9, cis-12-C18:2; HFLA = heated FLA $\left(150^{\circ} \mathrm{C}\right.$ for $\left.6 \mathrm{~h}\right) ; 13 \mathrm{HPOD}=13-\mathrm{OOH}$ cis-9, trans11-C18:2; HEX = pure hexanal; T2D = pure trans-2-decenal; PEN = pure pentanal; HEP $=$ pure heptanal; NON = pure nonanal; T2T4D = pure trans-2,trans-4-decadienal. 
Table 7. Capillary electrophoresis single-strand conformation polymorphism similarity values (R-ANOSIM) between the different treatments used in experiment 1 , combining 6- and 24-h incubations ${ }^{1}$

\begin{tabular}{lrccc}
\hline & \multicolumn{1}{c}{ FLA } & HFLA & 13HPOD & HEX \\
\hline HFLA & -0.138 & - & - & - \\
13HPOD & 0.615 & 0.888 & - & - \\
HEX & -0.138 & 0.052 & 0.325 & - \\
T2D & 0.037 & 0.415 & 0.278 & 0.251 \\
\hline
\end{tabular}

${ }^{1} \mathrm{FLA}=$ pure cis-9, cis-12-C18:2; HFLA = heated FLA $\left(150^{\circ} \mathrm{C}\right.$ for $\left.6 \mathrm{~h}\right)$; $13 \mathrm{HPOD}=13-\mathrm{OOH}$ cis-9,trans-11-C18:2; HEX = pure hexanal; T2D $=$ pure trans-2-decenal.

rumen metabolism toward another pathway of cis-9, cis12-C18:2, such as hydration, which can be performed by Streptococcus bovis (Hudson et al., 1998). With TGLA, the decrease in trans-11 isomers was greater than that of trans-10 isomers, showing that the balance between the 2 main $\mathrm{BH}$ pathways was affected.

With HFLA, despite a slightly lower initial quantity of cis-9,cis-12-C18:2 compared with other media, inhibition of cis-9,cis-12-C18:2 disappearance was observed because isomerization efficiency was decreased $(P<0.01)$. This inhibition was observed only on $\Delta^{12}-$ isomerization because only trans-11 isomers were decreased $(P<0.01)$. This great alteration of the trans-11 $\mathrm{BH}$ pathway with heating has been reported previously (Vázquez-Añón et al., 2008; Privé et al., 2010). This inhibition of $\Delta^{12}$-isomerization with HFLA could be linked to the presence of aldehydes or hydroperoxides.

Aldehydes are not important modulators of free cis9, cis-12-C18:2 BH or the ruminal bacterial community. Among them, T2D has been reported to increase BH (Lee et al., 2007), but the culture conditions in that experiment were different from ours; in particular, those authors did not add cis-9,cis-12-C18:2 to their cultures, so that their effects could be due to modifications of either lipolysis or $\mathrm{BH}$, and if these effects were on $\mathrm{BH}$ reactions, they could have been less obvious in our experiment using larger amounts of cis-9,cis-12-C18:2 as substrate. Lee et al. (2007) also observed a decrease in trans-10 isomers and cis-12-C18:1 and an increase in trans-11 isomers with T2D compared with other oxidative products, in particular other aldehydes, which was the case in our experiment 2 but not in experiment 1. In our experiment 2, T2T4D also slightly increased trans-11 isomers $(P<0.01)$. In fact, in our experiments, aldehydes had few and variable effects on $\mathrm{BH}$ so that no definite conclusions about their effects can be drawn. In a previous study in our laboratory (Kaleem et al., 2013), heating oilseeds decreased cis-9, cis-12-C18:2 disappearance, and we proposed 2 possible modes of action: an antimicrobial effect of aldehydes on ruminal bacteria or the formation of Maillard complexes during heating. In the present study, no effect of aldehydes on the bacterial community was observed.

In the present study, the major $\mathrm{BH}$ modulators were hydroperoxides. In particular, in enzymatic solutions, 13HPOD and 9HPOD led to an inhibition of trans-11 isomer production, and 9HPOD to an inhibition of production of both trans-11 and trans-10 isomers (Table 8). Moreover, 13HPOD in ruminal cultures led to an increase in trans-10 isomer production $(P<0.01$; Table $3)$. Such a modification of trans isomer production was reported by Privé et al. (2010), linked to increased peroxide values $(\mathbf{P V})$. As in the present study, Privé et al. (2010) found large effects on isomerization. Hence, hydroperoxides could explain, at least in part, the ef-

Table 8. Effects of hydroperoxides and aldehydes on the production ( $\mu \mathrm{g} /$ tube) of cis-9, cis-12-C18:2 biohydrogenation intermediates and final products in chloramphenicol-treated ruminal fluid initially containing $1 \mathrm{mg}$ of free cis-9,cis-12-C18:2, cis-9,trans-11-conjugated linoleic acid (CLA), trans-10, cis-12-CLA, or trans-11-C18:1 (experiment 3)

\begin{tabular}{|c|c|c|c|c|c|c|c|}
\hline \multirow[b]{2}{*}{ Production } & \multicolumn{5}{|c|}{ Culture $^{1}$} & \multirow[b]{2}{*}{ SEM } & \multirow[b]{2}{*}{$P$-value } \\
\hline & $\begin{array}{l}\text { No oxidative } \\
\text { product }\end{array}$ & $9 \mathrm{HPOD}$ & 13HPOD & HEX & $\mathrm{T} 2 \mathrm{~T} 4 \mathrm{D}$ & & \\
\hline $\begin{array}{l}\text { Incubation of trans-10, cis-12-CLA } \\
\text { trans-10-C18:1 } \\
\text { C18:0 }\end{array}$ & $\begin{array}{r}59^{\mathrm{a}} \\
433\end{array}$ & $\begin{array}{r}50^{\mathrm{b}} \\
426\end{array}$ & $\begin{array}{r}50^{\mathrm{b}} \\
427\end{array}$ & $\begin{array}{r}53^{\mathrm{b}} \\
413\end{array}$ & $\begin{array}{r}52^{\mathrm{b}} \\
427\end{array}$ & $\begin{array}{l}1 \\
8\end{array}$ & $\begin{array}{r}<0.01 \\
0.53\end{array}$ \\
\hline $\begin{array}{l}\text { Incubation of trans-11-C18:1 } \\
\text { C18:0 }\end{array}$ & 420 & 418 & 407 & 443 & 425 & 11 & 0.27 \\
\hline
\end{tabular}

${ }^{\mathrm{a}-\mathrm{C}}$ Means in the same row with different superscripts differ significantly $(P<0.05)$.

${ }^{1}$ 9HPOD $=$ pure 9-OOH trans-10,cis-12-C18:2; 13HPOD = pure 13-OOH cis-9,trans-11-C18:2; HEX = pure hexanal; T2T4D = pure trans2,trans-4-decadienal. 
fects of fat heating. In HFLA incubations, with large amounts of both 9HPOD and 13HPOD, trans-11 isomer production was greatly inhibited compared with 13HPOD alone (Tables 3 and 4). The 2 hydroperoxide isomers, as prooxidants, probably directly interfered with $\Delta^{12}$-isomerization because this reaction, like lipid oxidation, involves radicals (Wallace et al., 2007), so it could involve some intermediates chemically similar to 13 HPOD. An effect of hydroperoxides on the $\Delta^{12}$ isomerase would also be in agreement with the appearance and persistence of effects on trans-11 isomer production in 24-h incubations, because this enzyme is not recyclable (Kim et al., 2000). Indeed, as it cannot be reused, it becomes less and less available in the media. Moreover, HFLA did not affect the structure of bacterial community (Table 7) or its diversity and density (Table 6). However, an action via the bacterial population cannot be excluded because hydroperoxides have bacteriostatic effects that could not be assayed by our study, because inactivated bacterial DNA is detected as efficiently as DNA from active bacteria. Indeed, some peroxides (e.g., benzoyl peroxide) are used in medicine as potent oxidizing agents to treat skin infections, for example (Fanta et al., 1979). Furthermore, the CESSCP technique could have failed to reveal changes in the bacterial community affecting scarce bacteria; Butyrivibrio fibrisolvens and Butyrivibrio proteoclasticus, which are responsible for trans-11 isomerization, have low relative abundances in the rumen (Zened et al., 2013). Thus, hydroperoxides could partly explain the effects of highly oxidized fat on trans-11 isomers through inhibition of $\Delta^{12}$-isomerization or a bacteriostatic effect on trans-11 isomer-producing bacteria. Moreover, as 13HPOD was not as efficient as HFLA in decreasing trans-11 isomer production, some other compounds might be involved, such as 9HPOD.

In our experiment 1 , the increase in trans-10 isomer production was observed only in 13HPOD cultures with short incubations $(P<0.01$; Table 3$)$. Privé et al. (2010) also reported this increase of trans-10 isomers production when incubating rumen fluid for $6 \mathrm{~h}$ with a high $\mathrm{PV}$ oil $\left(\mathrm{PV}=238 \mathrm{mEq}\right.$ of $\mathrm{O}_{2} / \mathrm{kg}$ of oil corresponding to $75 \mathrm{mg}$ of hydroperoxides with 18 carbons and 2 double bonds, which is similar to the $85 \mathrm{mg}$ of total hydroperoxides per $\mathrm{kg}$ of added fat in our 13HPOD cultures). In HFLA incubations in the present experiment, there was probably insufficient 13HPOD to result in a measurable increase of trans-10 production (i.e., $25 \mathrm{mg}$ of total hydroperoxides per $\mathrm{kg}$ of added fat). This evolution of trans-10 isomers was concomitant with a modification of the bacterial community by $13 \mathrm{HPOD}$, in particular compared with FLA (R-ANOSIM $=0.62)$, whereas FLA and HFLA did not result in different communities
$(\mathrm{R}-\mathrm{ANOSIM}=-0.14 ;$ Table 7$)$. Similarly, Privé et al. (2010) observed a modification of the bacterial community without any change in its diversity when adding heated oil to ruminal cultures. Thus, 13HPOD could be partly responsible for the increase of trans-10 isomers observed with highly oxidized fat, shifting the bacterial community toward trans-10-producing bacteria. Such an effect did not persist in 24-h incubations because hydroperoxides are not stable molecules (Frankel, 2005), especially under the reducing conditions observed in the rumen, so that they were probably rapidly broken down in our incubations, showing a strong resilience of the rumen microbiota after a disturbance caused by oxidative products. On the other hand, 13HPOD did not significantly affect $\Delta^{9}$-isomerization, whereas 9HPOD decreased it (Table 8). Indeed, this reaction is quite different from $\Delta^{12}$-isomerization and would have a carbocation chemically similar to trans-10, cis-12-CLA as an intermediate (Liavonchanka et al., 2006). This could explain why only 9HPOD could inhibit this reaction.

Hence, in HFLA, there was probably insufficient 13HPOD to modify the ruminal population and increase trans-10 isomer production, and an insufficient amount of 9HPOD to significantly decrease trans-10 production, but 13HPOD and 9HPOD together inhibited production of trans-11 isomers. In HTGLA cultures, $\mathrm{BH}$ was likely affected in a same way.

\section{CONCLUSIONS}

Polymers of TAG did not affect cis-9,cis-12-C18:2 disappearance. Heating FLA and TGLA greatly inhibited $\Delta^{12}$-isomerization, leading to decreased cis9,cis-12-C18:2 disappearance. This may have occurred because of the production of hydroperoxides and aldehydes during heat treatment. Neither bacterial community nor disappearance of cis-9,cis-12-C18:2 was affected by chain length or degree of unsaturation of aldehydes, and aldehydes only slightly affected $\mathrm{BH}$ intermediates. Among hydroperoxides, 9HPOD inhibited $\Delta^{9}$-isomerization and $\Delta^{12}$-isomerization, whereas 13HPOD only inhibited $\Delta^{12}$-isomerization but it also affected the structure of the bacterial community, resulting in increased production of trans-10 isomers. Thus, hydroperoxides could explain (1) the increased trans-10 isomer production observed with highly oxidized fat associated with a modification of the bacterial population due to $13 \mathrm{HPOD}$; and (2) the decrease in trans-11 isomer production with heated oil, caused by the inhibiting effect of 13HPOD and 9HPOD on $\Delta^{12}$-isomerization. Nevertheless, some other oxidative products might also be involved. 


\section{ACKNOWLEDGMENTS}

The authors thank M. L. Chemit, B. Gabinaud, S. Combes, L. Cauquil, and the staff at the experimental station (UMR 1289 Tandem, France).

\section{REFERENCES}

AFNOR. 2000. Détermination de la teneur en triglycérides polymérisés par chromatographe liquide d'exclusion à haute performance (CLHP d'exclusion); Corps gras d'origines animale et végétale. In Collection de Normes Françaises et de Méthodes Communautaires. Aliments des Animaux. Méthodes d'Analyse. AFNOR ISO 16931. Association Française de Normalisation (AFNOR), Paris, France.

Allison, J. L., R. E. Hartman, R. S. Hartman, A. D. Wolfe, J. Ciak, and F. E. Hahn. 1962. Mode of action of chloramphenicol. J. Bacteriol. 83:609-615.

Brioukhanov, A. L., and A. I. Netrusov. 2004. Catalase and superoxide dismutase: Distribution, properties, and physiological role in cells of strict anaerobes. Biochemistry (Mosc.) 69:949-962.

Browne, R. W., and D. Armstrong. 2000. HPLC analysis of lipidderived polyunsaturated fatty acid peroxidation products in oxidatively modified human plasma. Clin. Chem. 46:829-836.

Chilliard, Y., C. Martin, J. Rouel, and M. Doreau. 2009. Milk fatty acids in dairy cows fed whole crude linseed, extruded linseed, or linseed oil, and their relationship with methane output. J. Dairy Sci. 92:5199-5211.

Chouinard, P. Y., V. Girard, and G. J. Brisson. 1997a. Performance and profiles of milk fatty acids of cows fed full fat, heat-treated soybeans using various processing methods. J. Dairy Sci. 80:334342

Chouinard, P. Y., J. Lévesque, V. Girard, and G. J. Brisson. 1997b. Dietary soybeans extruded at different temperatures: Milk composition and in situ fatty acid reactions. J. Dairy Sci. 80:2913-2924.

Combes, S., R. J. Michelland, V. Monteils, L. Cauquil, V. Soulié, N. U. Tran, T. Gidenne, and L. Fortun-Lamothe. 2011. Postnatal development of the rabbit caecal microbiota composition and activity. FEMS Microbiol. Ecol. 77:680-689.

Delbès, C., R. Moletta, and J. J. Godon. 2000. Monitoring of activity dynamics of an anaerobic digester bacterial community using 16S rRNA polymerase chain reaction single-strand conformation polymorphism analysis. Environ. Microbiol. 2:506-515.

Deng, W., T. R. Hamilton-Kemp, M. T. Nielsen, R. A. Andersen, G. B. Collins, and D. F. Hildebrand. 1993. Effects of six-carbon aldehydes and alcohols on bacterial proliferation. J. Agric. Food Chem. 41:506-510.

Enjalbert, F., and A. Troegeler-Meynadier. 2009. Biosynthesis of trans fatty acids in ruminants. Pages 1-31 in Trans Fatty Acids in Human Nutrition. F. Destaillats, J.-L. Sebedio, F. Dionisi, and J. M. Chardigny, ed. The Oily Press, Bridgewater, UK.

Fanta, D., H. Bardach, and C. Poitscheck. 1979. Investigations on the bacteriostatic effect of benzoyl peroxide. Arch. Dermatol. Res. 264:369-371.

Fauconnier, M.-L., A. G. Perez, C. Sanz, and M. Marlier. 1997. Purification and characterization of tomato leaf (Lycopersicon esculentum Mill.) hydroperoxide lyase. J. Agric. Food Chem. 45:42324236.

Fierer, N., J. A. Jackson, R. Vilgalys, and R. B. Jackson. 2005. Assessment of soil microbial community structure by use of taxonspecific quantitative PCR assays. Appl. Environ. Microbiol. 71:4117-4120.

Frankel, E. N. 2005. Lipid Oxidation. 2nd ed. The Oily Press, Bridgewater, UK.

Gebauer, S. K., J. M. Chardigny, M. U. Jakobsen, B. Lamarche, A L. Lock, S. D. Proctor, and D. J. Baer. 2011. Effects of ruminant trans fatty acids on cardiovascular disease and cancer: A comprehensive review of epidemiological, clinical, and mechanistic studies. Adv. Nutr. 2:332-354.

Gonthier, C., A. F. Mustafa, D. R. Ouellet, P. Y. Chouinard, R. Berthiaume, and H. V. Petit. 2005. Feeding micronized and extruded flaxseed to dairy cows: Effects on blood parameters and milk fatty acid composition. J. Dairy Sci. 88:748-756.

Griinari, J. M., B. A. Corl, S. H. Lacy, P. Y. Chouinard, K. V. V. Nurmela, and D. E. Bauman. 2000. Conjugated linoleic acid is synthesized endogenously in lactating dairy cows by $\Delta 9$-desaturase. J. Nutr. 130:2285-2291.

Hudson, J. A., B. Morvan, and K. N. Joblin. 1998. Hydration of linoleic acid by bacteria isolated from ruminants. FEMS Microbiol Lett. 169:277-282

Kaleem, M., Y. Farizon, F. Enjalbert, and A. Troegeler-Meynadier. 2013. Lipid oxidation products of heated soybeans as a possible cause of protection from ruminal biohydrogenation. Eur. J. Lipid Sci. Technol. 115:161-169.

Kim, Y. J., R. H. Liu, D. R. Bond, and J. B. Russell. 2000. Effect of linoleic acid concentration on conjugated linoleic acid production by Butyrivibrio fibrisolvens A38. Appl. Environ. Microbiol. 66:5226-5230.

Kim, Y. J., R. H. Liu, J. L. Rychlik, and J. B. Russell. 2002. The enrichment of a ruminal bacterium (Megasphaera elsdenii YJ-4) that produces the trans-10, cis-12 isomer of conjugated linoleic acid. J. Appl. Microbiol. 92:976-982.

Kubo, A., C. S. Lunde, and I. Kubo. 1995. Antimicrobial activity of the olive oil flavor compounds. J. Agric. Food Chem. 43:16291633.

Lee, M. R. F., S. A. Huws, N. D. Scollan, and R. J. Dewhurst. 2007. Effects of fatty acid oxidation products (green odor) on rumen bacterial populations and lipid metabolism in vitro. J. Dairy Sci. 90:3874-3882

Li, N., C. Deng, N. Yao, X. Shen, and X. Zhang. 2005. Determination of acetone, hexanal and heptanal in blood samples by derivatization with pentafluorobenzyl hydroxylamine followed by headspace single-drop microextraction and gas chromatography-mass spectrometry. Anal. Chim. Acta 540:317-323.

Liavonchanka, A., E. Hornung, I. Feussner, and M. G. Rudolph. 2006. Structure and mechanism of the Propionibacterium acnes polyunsaturated fatty acid isomerase. Proc. Natl. Acad. Sci. USA 103:2576-2581.

López-Nicolás, J. M., M. Pérez-Gilabert, and F. García-Carmona. 1999. Rapid reversed-phase high-performance liquid chromatographic determination of the regiospecificity of lipoxygenase products on linoleic acid. J. Chromatogr. A 859:107-111.

Michelland, R. J., S. Dejean, S. Combes, L. Fortun-Lamothe, and L. Cauquil. 2009. StatFingerprints: A friendly graphical interface program for processing and analysis of microbial fingerprint profiles. Mol. Ecol. Resour. 9:1359-1363.

Park, P. W., and R. E. Goins. 1994. In situ preparation of fatty acid methyl esters for analysis of fatty acid composition in foods. J. Food Sci. 59:1262-1266.

Privé, F., S. Combes, L. Cauquil, Y. Farizon, F. Enjalbert, and A. Troegeler-Meynadier. 2010. Temperature and duration of heating of sunflower oil affect ruminal biohydrogenation of linoleic acid in vitro. J. Dairy Sci. 93:711-722.

Reddy, P. V., J. L. Morrill, and T. G. Nagaraja. 1994. Release of free fatty acids from raw of processed soybeans and subsequent effects on fiber digestibilities. J. Dairy Sci. 77:3410-3416.

Rosenzweig, M. L. 1995. Species Diversity in Space and Time. Cambridge University Press, Cambridge, UK.

Tarvainen, M., J.-P. Suomela, A. Kuksis, and H. Kallio. 2010. Liquid chromatography-light scattering detector-mass spectrometric analysis of digested oxidized rapeseed oil. Lipids 45:1061-1079.

Troegeler-Meynadier, A., L. Bret-Bennis, and F. Enjalbert. 2006a Rates and efficiencies of reactions of ruminal biohydrogenation of linoleic acid according to $\mathrm{pH}$ and polyunsaturated fatty acids concentrations. Reprod. Nutr. Dev. 46:713-724.

Troegeler-Meynadier, A., and F. Enjalbert. 2005. Les acides linoléiques conjugués: 1. Intérêts biologiques en nutrition. Rev. Med. Vet. (Toulouse) 156:207-216.

Troegeler-Meynadier, A., M. C. Nicot, and F. Enjalbert. 2006b. Effects of heating process of soybeans on ruminal production of conjugated linoleic acids and trans-octadecenoic acids in situ. Rev Med. Vet. (Toulouse) 157:509-514. 
Vázquez-Añón, M., J. Nocek, G. Bowman, T. Hampton, C. Atwell, P. Vázquez, and T. Jenkins. 2008. Effects of feeding a dietary antioxidant in diets with oxidized fat on lactation performance and antioxidant status of the cow. J. Dairy Sci. 91:3165-3172.

Wallace, R. J., N. McKain, K. J. Shingfield, and E. Devillard. 2007. Isomers of conjugated linoleic acids are synthesized via different mechanisms in ruminal digesta and bacteria. J. Lipid Res. 48:2247-2254.

Zened, A., C. Combes, L. Cauquil, J. Mariette, C. Klopp, O. Bouchez, A. Troegeler-Meynadier, and F. Enjalbert. 2013. Microbial ecology of the rumen evaluated by 454 GS FLX pyrosequencing is affected by starch and oil supplementation of diets. FEMS Microbiol. Ecol. 83:504-514.

Zened, A., A. Troegeler-Meynadier, M. C. Nicot, S. Combes, L. Cauquil, Y. Farizon, and F. Enjalbert. 2011. Starch and oil in the donor cow diet and starch in substrate differently affect the in vitro ruminal biohydrogenation of linoleic and linolenic acids. J. Dairy Sci. 94:5634-5645.

Zumstein, E., R. Moletta, and J. J. Godon. 2000. Examination of two years of community dynamics in an anaerobic bioreactor using fluorescence polymerase chain reaction (PCR) single-strand conformation polymorphism analysis. Environ. Microbiol. 2:69-78. 